Article

\title{
A Porous Cobalt (II) Metal-Organic Framework with Highly Efficient Electrocatalytic Activity for the Oxygen Evolution Reaction
}

\author{
Qingguo Meng ${ }^{1}{ }^{\mathbb{D}}$, Jianjian Yang ${ }^{1}$, Shixuan $\mathrm{Ma}^{1}$, Mujun Zhai ${ }^{2}$ and Jitao Lu ${ }^{1, *}$ \\ 1 College of Chemical Engineering and Environmental Chemistry, Weifang University, Weifang 261061, China; \\ mengqg@wfu.edu.cn (Q.M.); jitaolu@wfu.edu.cn (J.Y.); wfumqg@163.com (S.M.) \\ 2 The Testing Center of Shandong Bureau of China Metallurgy and Geology Bureau, Jinan 250014, China; \\ zhaimujunyangjia@163.com \\ * Correspondence: lujitao@foxmail.com; Tel.: +86-0536-8785361
}

Received: 6 November 2017; Accepted: 30 November 2017; Published: 6 December 2017

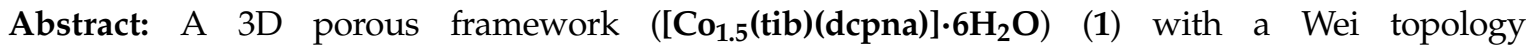
has been synthesized by solvothermal reaction of 1,3,5-tris(1-imidazolyl)-benzene (tib), 5-(3',5'-dicarboxylphenyl)nicotinic acid ( $\left.\mathrm{H}_{3} \mathrm{dcpna}\right)$ and cobalt nitrate. The electrocatalytic activity for water oxidation of $\mathbf{1}$ has been investigated in alkaline solution. Compound $\mathbf{1}$ exhibits good oxygen evolution reaction (OER) activities in alkaline solution, exhibiting $10 \mathrm{~mA} \cdot \mathrm{cm}^{-2}$ at $\eta=360 \mathrm{mV}$ with a Tafel slope of $89 \mathrm{mV} \cdot \mathrm{dec}^{-1}$. The high OER activity can be ascribe to 1D open channels along b axis of $\mathbf{1}$, which expose more activity sites and facilitate the electrolyte penetration.
\end{abstract}

Keywords: cobalt; metal-organic frameworks; Wei topology; oxygen evolution reaction

\section{Introduction}

Electrochemical splitting of water into $\mathrm{H}_{2}$ and $\mathrm{O}_{2}$ is one of the effective and environmentally friendly methods for a possible hydrogen economy [1-5]. The water electrolysis is composed of two half reactions: the hydrogen evolution reaction (HER, $2 \mathrm{H}^{+}+2 \mathrm{e}^{-} \rightarrow \mathrm{H}_{2}$ in acidic electrolytes) and the oxygen evolution reaction (OER, $4 \mathrm{OH}^{-} \rightarrow 2 \mathrm{H}_{2} \mathrm{O}+4 \mathrm{e}^{-}+\mathrm{O}_{2}$ in alkaline electrolytes) [6-9]. OER is a demanding step which involves multiproton-coupled electron-transfers and oxygen-oxygen bond formation. Hence, OER has a high activation energy barrier and requires a higher energy (higher overpotential) to overcome the kinetic barrier [10-12]. To facilitate energy storage and conversion systems, such as batteries, supercapacitors and water splitting, plenty of efficient and stable OER electrocatalysts have been exploited [13-15]. Among which, precious-metal oxides such as $\mathrm{IrO}_{2}$ and $\mathrm{RuO}_{2}$ are well known as the most active electrocatalysts for the OER in both acidic and alkaline electrolytes due to their low overpotential and small Tafel slope [16-19]. However, both are made of precious metals which render them unsuitable for use in largescale practical applications. Therefore, substantial research effort has been devoted to explore non-noble metal catalysts with high electrocatalytic activity and stability, such as 3d-transition-metal oxides, perovskites, transition-metal sulfides, hydro(oxy)oxides, phosphates, non-metal compounds and molybdates, along with various molecular catalysts [20-26]. Among these well-developed electrocatalysts, 3d-transition metal compounds, especially cobalt-based compounds, have attracted growing research interests and have exhibited high electrocatalytic activity for OER due to their various redox properties and unusual capability to form high-oxidation cobalt species during OER process $[27,28]$.

As a new type of porous material, porous metal-organic frameworks (MOFs), which are built from metal-based nodes and organic linkers, are often considered as ideal alternatives in important catalytic processes owing to their inherent features, such as large surface area, unique porosity and tailorable 
functionality [29-34]. In particular, some reports show that MOFs possess high electrocatalytic activity for OER owing to its high surface areas, which exposed more active site. For example, Sun's group have reported a $3 \mathrm{D}$ non-interpenetrating porous metal-organic framework $\left[\mathrm{Pb}_{2}\left(\mathrm{H}_{2} \mathrm{TCPP}\right)\right] \cdot 4 \mathrm{DMF} \cdot \mathrm{H}_{2} \mathrm{O}$ (Pb-TCPP) $\left(\mathrm{H}_{6} \mathrm{TCPP}=5,10,15,20\right.$-tetra(carboxyphenyl)porphyrin, $\mathrm{DMF}=(\mathrm{N}, \mathrm{N}$-dimethylformamide), which shows electrocatalytic activity in alkaline electrolytes [35]. However, lead is a kind of toxic metal, which is not desired in practical applications. Wang's group synthesized a highly stable $\mathrm{Fe} / \mathrm{Ni}$ metal-organic framework by electrochemical deposition. This mixed-metal MOF film-based electrode shows high activity with low overpotential of $270 \mathrm{mV}$ at $10 \mathrm{~mA} \cdot \mathrm{m}^{-2}$, high current densities and a small Tafel slope of $47 \mathrm{mV} \cdot \mathrm{dec}^{-1}$ [36]. Despite there are numerous advantages of MOFs used as electrocatalysts for OER, the directly use of MOFs for electrocatalytic OER is still in its infancy.

In the present work, a porous metal-organic frameworks $\left(\left[\mathrm{Co}_{1.5}(\mathrm{tib})(\mathrm{dcpna})\right] \cdot \mathbf{6} \mathrm{H}_{\mathbf{2}} \mathrm{O}\right)(\mathbf{1})$ based on 1,3,5-tris(1-imidazolyl)-benzene (tib) and 5-(3',5'-dicarboxylphenyl)nicotinic acid ( $\mathrm{H}_{3} \mathrm{dcpna}$ ) has been synthesized and characterized. Single-crystal X-ray diffraction analysis reveals that 1 exhibits a non-penetrated 3D porous framework. The electrocatalytic activity for water oxidation of $\mathbf{1}$ has been investigated in alkaline solution. Compound 1 exhibits a good oxygen evolution reaction (OER) activities at a low overpotential of $360 \mathrm{mV}$ for $10 \mathrm{~mA} \cdot \mathrm{cm}^{-2}$ current density with a Tafel slope of $89 \mathrm{mV} \cdot \mathrm{dec}^{-1}$ in $1 \mathrm{M} \mathrm{KOH}$.

\section{Experimental}

\subsection{Materials and Methods}

All chemicals were of reagent grade and purchased from commercial vendors without further purification. Elemental analyses were recorded on a Perkin-Elmer 240 elemental analyzer(PerkinElmer, Inc., Billerica, MA, USA). Powder X-ray diffraction (PXRD) measurements were conducted with a Bruker AXS D8 Advance instrument (Karlsruhe, Germany). The Fourier Transform Infrared (FT-IR) spectra were recorded on a Nicolet 330 FTIR Spectrometer (Nicolet Instrument Inc., Madison, WI, USA) in the range of $4000-400 \mathrm{~cm}^{-1}$ using the $\mathrm{KBr}$ pellet method. TGA experiments were carried out on a Perkin-Elmer TGA 7 instrument (PerkinElmer, Billerica, MA, USA) with heating rate of $10{ }^{\circ} \mathrm{C} \mathrm{min}^{-1}$ under nitrogen stream. All electrochemical measurements were performed on a CHI760E electrochemical workstation (Chenhua Instrument Shanghai Co., Ltd., Shanghai, China).

\subsection{Synthesis of $\left[\mathrm{Co}_{1.5}(\mathrm{tib})(\right.$ dcpna $\left.)\right] \cdot 6 \mathrm{H}_{2} \mathrm{O}(\mathbf{1})$}

A mixture of tib (0.018 mmol, $5 \mathrm{mg}), \mathrm{H}_{3}$ dcpna $(0.023 \mathrm{mmol}, 6.6 \mathrm{mg})$ and $\mathrm{Co}\left(\mathrm{NO}_{3}\right)_{2} \cdot 6 \mathrm{H}_{2} \mathrm{O}$ $(0.034 \mathrm{mmol}, 10 \mathrm{mg})$ were dissolved in $6 \mathrm{~mL}$ of mixed solvents of $\mathrm{DMF} / 1,4$-dioxane $/ \mathrm{H}_{2} \mathrm{O}(v / v / v=2.5: 1: 1)$. After performing an ultrasound at room temperature for $10 \mathrm{~min}$, the glass tube was sealed and placed in an oven and slowly heated to $80^{\circ} \mathrm{C}$ from room temperature in $700 \mathrm{~min}$, kept at $80^{\circ} \mathrm{C}$ for 3 days and slowly cooled to $35^{\circ} \mathrm{C}$ in $1000 \mathrm{~min}$. Then, the glass tube was slowly heated to $120^{\circ} \mathrm{C}$ in $700 \mathrm{~min}$ and kept at $120^{\circ} \mathrm{C}$ for 3 days. After cooling down to room temperature in $1000 \mathrm{~min}$, violet block-shaped crystals suitable for X-ray diffraction analysis were separated by filtration with the yield of $8.853 \mathrm{mg}, 51.6 \%$ (based on cobalt). Anal. Calc. (found) for $\mathrm{C}_{29} \mathrm{H}_{40} \mathrm{O}_{12} \mathrm{~N}_{7} \mathrm{Co}_{1.5}$ : C, 45.41 (45.34); $\mathrm{H}, 5.26$ (5.71), N 12.78 (13.24) IR $(\mathrm{KBr}): \mathrm{m}\left(\mathrm{cm}^{-1}\right)=3434(\mathrm{w}), 1614(\mathrm{~s}), 1542(\mathrm{~s}), 1513(\mathrm{~s}), 1438(\mathrm{~s}), 1409(\mathrm{~m}), 1369(\mathrm{~m}), 1294(\mathrm{w}), 1261(\mathrm{~m})$, $1116(\mathrm{w}), 1074(\mathrm{~m}), 1010(\mathrm{~m}), 856(\mathrm{w}), 777(\mathrm{~m}), 734(\mathrm{~m}), 651(\mathrm{~m}), 4417(\mathrm{w})$.

\subsection{X-ray Crystallography}

The unit cell determinations and data collections for the Single crystal of $\mathbf{1}$ were performed on a Bruker D8 Apex II Image Plate single-crystal diffractometer. The data were collected using a graphite monochromated Mo K $\alpha$ radiation source $(\lambda=0.71073 \AA)$ at $293 \mathrm{~K}$. All absorption corrections were performed by the multi-scan program SADABS [37]. In all cases, the highest possible space group was chosen. The structure was solved by direct methods and refined on $F^{2}$ by full-matrix least-squares procedures with SHELXL-97 program package [38,39]. As no appropriate disorder model can be 
used to deal with the highly disordered solvent molecules, the SQUEEZE subroutine of the PLATON software suit was used to remove scattering from the disordered solvent molecules [40]. The following new files were used to further refine the structures. The Crystal data and structure refinement for $\mathbf{1}$ are listed in Table 1. Selected bond lengths and angles for $\mathbf{1}$ are summarized in Table 2. The Cambridge Crystallographic Data Centre (CCDC)-1579569 contains the supplementary crystallographic data for this paper. These data can be obtained free of charge at www.ccdc.cam.ac.uk/conts/retrieving.html or from the Cambridge Crystallographic Data Centre, 12, Union Road, Cambridge CB2 1EZ, UK; fax: (internat.) +44-1223/336-033; email: deposit@ccdc.cam.ac.uk.

Table 1. Crystal data and structure refinement for $\mathbf{1}$.

\begin{tabular}{|c|c|}
\hline Complex & 1 \\
\hline Empirical formula & $\mathrm{C}_{29} \mathrm{H}_{18} \mathrm{Co}_{1.5} \mathrm{~N}_{7} \mathrm{O}_{6}$ \\
\hline Formula weight & 648.90 \\
\hline Temperature/K & $293(2)$ \\
\hline Crystal system & monoclinic \\
\hline Space group & $C 2 / c$ \\
\hline$a / \AA$ & $35.366(7)$ \\
\hline$b / \AA$ & $9.2025(18)$ \\
\hline$c / \AA$ & $25.003(5)$ \\
\hline$\alpha /{ }^{\circ}$ & 90.00 \\
\hline$\beta /{ }^{\circ}$ & $124.34(3)$ \\
\hline$\gamma /{ }^{\circ}$ & 90.00 \\
\hline Volume $/ \AA^{3}$ & $6719(2)$ \\
\hline Z & 8 \\
\hline$\rho_{\text {calc }} \mathrm{g} / \mathrm{cm}^{3}$ & 1.283 \\
\hline$\mu / \mathrm{mm}^{-1}$ & 0.797 \\
\hline$F(000)$ & 2636.0 \\
\hline Crystal size $/ \mathrm{mm}^{3}$ & $0.29 \times 0.25 \times 0.18$ \\
\hline Radiation & $\operatorname{MoK} \alpha(\lambda=0.71000)$ \\
\hline $2 \Theta$ range for data collection $/{ }^{\circ}$ & 6.08 to 54.9 \\
\hline Index ranges & $-45 \leq h \leq 45,-11 \leq k \leq 9,-32 \leq l \leq 31$ \\
\hline Reflections collected & 31073 \\
\hline Independent reflections & $7671\left[R_{\text {int }}=0.0698, R_{\text {sigma }}=0.0717\right]$ \\
\hline Data/restraints/parameters & $7671 / 0 / 393$ \\
\hline Goodness-of-fit on $F^{2}$ & 1.012 \\
\hline Final $R$ indexes $[\mathrm{I} \geq 2 \sigma(\mathrm{I})]$ & $R_{1}=0.0547, w R_{2}=0.1418$ \\
\hline Final $R$ indexes [all data] & $R_{1}=0.0959, w R_{2}=0.1685$ \\
\hline Largest diff. peak/hole/e $\AA^{-3}$ & $0.53 /-0.58$ \\
\hline
\end{tabular}

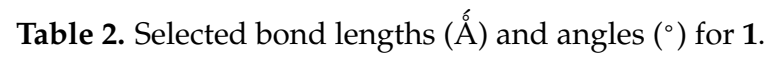

\begin{tabular}{cccccc}
\hline Co1-O5 & $1.993(3)$ & Co1-N7 & $2.047(3)$ & Co2-O3 & $2.059(2)$ \\
Co2-O1 & $2.128(2)$ & Co2-O4 & $2.296(3)$ & Co2-O2 & $2.194(3)$ \\
Co2-N1 & $2.092(3)$ & O5 ${ }^{1}$-Co1-O5 & $126.18(17)$ & O5-Co1-N7 1 & $108.31(12)$ \\
O5 ${ }^{1}$-Co1-N7 1 & $106.78(12)$ & N7 ${ }^{1-C o 1-N 7 ~}$ & $96.47(17)$ & O3-Co2-O1 & $157.03(12)$ \\
O3-Co2-O4 & $60.35(9)$ & O3-Co2-O2 & $101.56(11)$ & O3-Co2-N1 & $96.76(11)$ \\
O1-Co2-O4 & $103.00(10)$ & O1-Co2-O2 & $60.64(10)$ & O2-Co2-O4 & $90.64(11)$ \\
N1-Co2-O1 & $98.04(11)$ & N1-Co2-O4 & $156.94(10)$ & N1-Co2-O2 & $91.53(12)$ \\
N2-Co2-O3 & $97.93(11)$ & N2-Co2-O1 & $97.79(11)$ & N2-Co2-O4 & $90.13(11)$ \\
N2-Co2-O2 & $157.97(11)$ & N2-Co2-N1 & $96.31(12)$ & & \\
\hline \multicolumn{7}{c}{$11-\mathrm{X},+\mathrm{Y}, 1 / 2-\mathrm{Z}}$.
\end{tabular}

\subsection{Experiment for Electrochemical Measurements}

A glassy carbon electrode (GCE) with the diameter of $3.0 \mathrm{~mm}$ (Chenhua Instrument Shanghai Co., Ltd., China) was used as work electrode. Before electrochemical test, the surface of the GCE was 
rubbed carefully with alumina slurry and rinsed with ethanol and deionization water successively. A conventional three-electrode system was used with Saturated calomel electrode (SCE) as the reference electrode and Platinum (Pt) foil as counter electrode (surface area of $15 \mathrm{~mm} \times 15 \mathrm{~mm}$ ). The potential values are corrected to the reverse hydrogen electrode (RHE) according the equation $\mathrm{E}$ (RHE) $=\mathrm{E}$ (SCE) $+0.245+0.0591 \mathrm{pH}$ V. Typically, $5.0 \mathrm{mg}$ of $\mathbf{1}$ and $20.0 \mu \mathrm{L}$ Nafion solution $(5 \mathrm{wt} \%)$ were dispersed in $1 \mathrm{~mL}$ of mixed solvents of deionized water and ethanol $(v / v=1: 1)$ to form a homogeneous solution. Then, $10.0 \mu \mathrm{L}$ of the homogeneous solution was put on a glassy carbon electrode to prepare the work electrode. The geometric area of GCE is $0.07069 \mathrm{~cm}^{2}$. To achieve a constant state of the anodic electrode, the catalyst was electrochemically pre-activated by 15 cyclic voltammetry scans at a scan rate of $10 \mathrm{mV} \cdot \mathrm{s}^{-1}$ before the electrochemical test. Linear sweep voltammogram curves were examined in $2 \mathrm{M} \mathrm{KOH}(\mathrm{pH}=14.3), 1 \mathrm{M} \mathrm{KOH}(\mathrm{pH}=14.0)$ and $0.1 \mathrm{M} \mathrm{KOH}(\mathrm{pH}=13.0)$ for electro-catalysts, respectively. The scan rate is $10 \mathrm{mV} \cdot \mathrm{s}^{-1}$ and the scan region ranges from 0 to $0.9 \mathrm{~V} v \mathrm{vs}$. SCE.

\subsection{Calculation Method of the Turnover Frequency (TOF)}

TOF was calculated with Equation (1):

$$
\mathrm{TOF}=\frac{j A}{4 n F}
$$

where $j$ is the measured current density $\left(\mathrm{mA} \cdot \mathrm{cm}^{-2}\right)$ at a measured overpotential in the range of $343 \mathrm{mV}$ to $393 \mathrm{mV}, A$ is the geometric area of the GCE, $n$ is the mole number of the coated catalysts, and $F$ is the Faraday constant $\left(96,500 \mathrm{C} \cdot \mathrm{mol}^{-1}\right)$.

\section{Results and Discussion}

\subsection{X-ray Single Crystal Structure}

X-ray single-crystal diffraction analysis reveals that $\mathbf{1}$ possesses a neutral three-dimensional metal-organic framework with Wei topology, which is rare in the literature. It is crystallized in monoclinic $\mathrm{C} 2 / \mathrm{c}$ space group and there are one and a half $\mathrm{Co}(\mathrm{II})$ ions, one dcpna ligand, and one tib ligand in the asymmetrical unit of $\mathbf{1}$. The coordination environment of both of the two Co(II) ions are shown in Figure 1A. As can be seen, Co1 is tetra-coordinated with two carboxylate oxygen atoms (Co1-O5 1.993(3) ̊) from two different dcpna ligands and two $\mathrm{N}$ atoms of two different tib ligands (Co1-N7 2.047(3) $\AA$ ), forming a distorted tetrahedron geometry, while Co2 center has a distorted octahedral geometry. As depicted in Figure 1A, $\mathrm{Co} 2$ is six-coordinated by four carboxylate oxygen atoms and one $\mathrm{N}$ atom from three dcpna ligands and one $\mathrm{N}$ atom from a tib ligand. The bond distances of Co-O vary from 2.059(2) $\AA$ to 2.296(3) $\AA$, the distances of Co-N are 2.092(3) $\AA$ and 2.054(3) $\AA$, which are comparable with those for other reported Co compounds [41,42]. In 1, in combination with two $\mu_{2}$-tib, two $\mu_{4}$-dcpna ligands whose three carboxylate groups adopt $\mu_{1}-\eta^{1}-\eta^{1}$ and $\mu_{1}-\eta^{1}-\eta^{0}$ coordination mods link four Co(II) ions to form a coplanar structure with two 21-membered-rings and one 18-membered-ring (Figure 1B). Then, the neighbor coplanar structures connected to each other to furnish an open 3D frameworks through the coordination of carboxylate groups of dcpna ligand and $\mathrm{Co}(\mathrm{II})$ ions (Figure 1C). The structure shows small 1D channels along $\mathrm{b}$ axis, in which the disordered solvent molecules reside. The approximate channel sizes for $\mathbf{1}$ is $3.9 \times 5.1 \AA^{2}$. The percent void volume obtained using the PLATON software is $30.4 \%$ in the 3D networks of 1.

The topological method is used to simplify the structure of 1, Figure 1D. Topologically, both Co(II) ion and dcpna ligand can be seen as a 4-connected node, and then the overall 3D framework can be rationalized as a 4,4-conected network with the point symbols $\left\{3 \cdot 4 \cdot 6 \cdot 7 \cdot 8^{2}\right\} 4\left\{3^{2} \cdot 6^{2} \cdot 7^{2}\right\}$ and belongs to a Wei topology. 


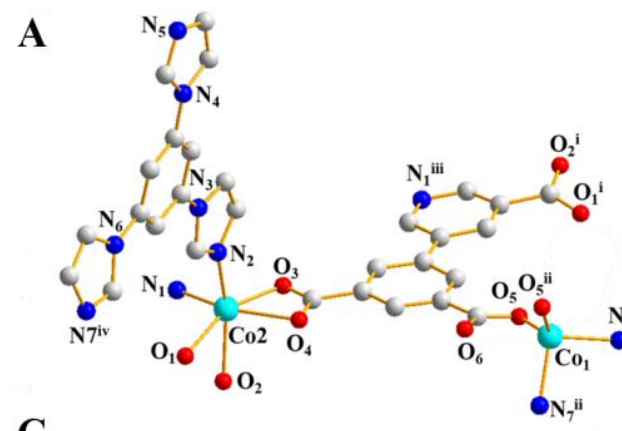

B
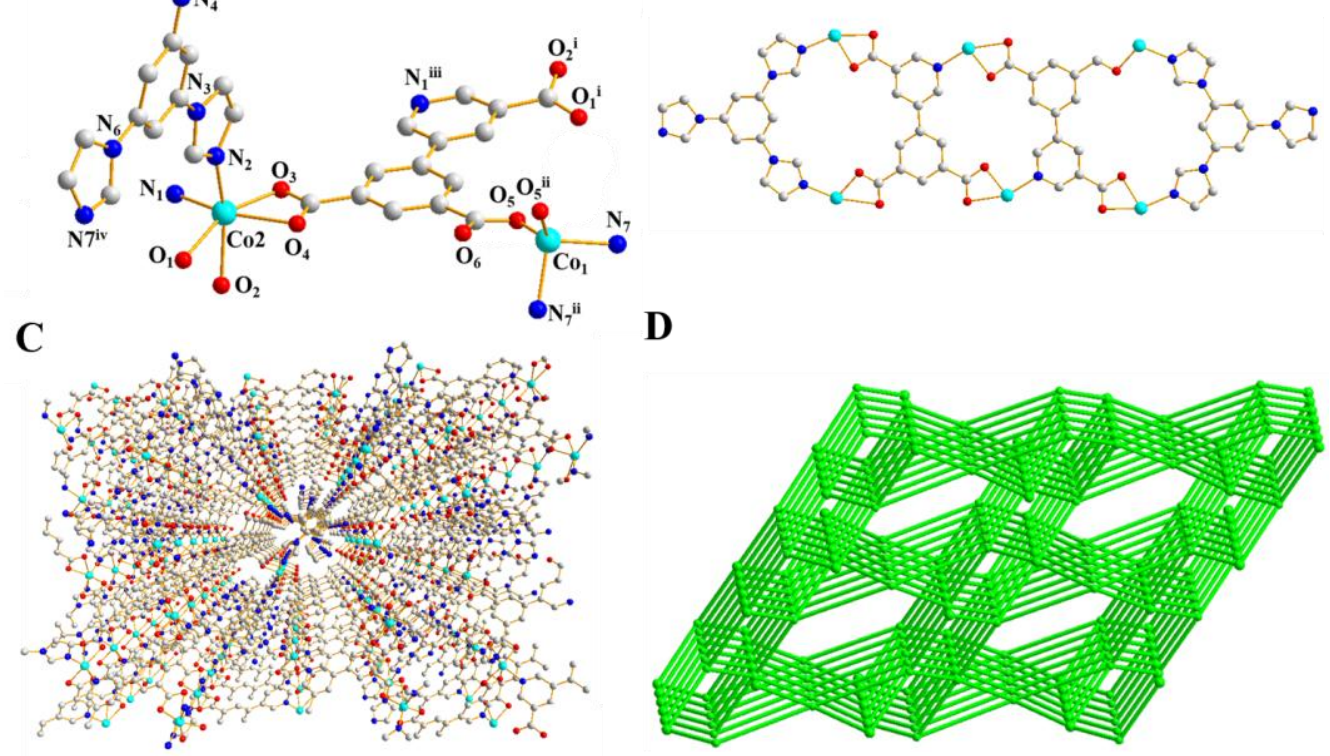

D

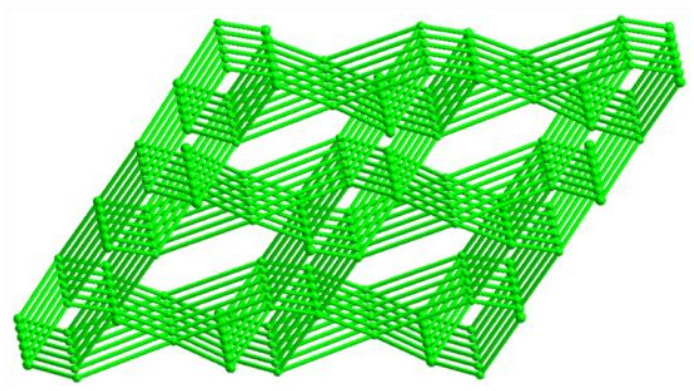

Figure 1. (A) The coordination environment of two Co(II) ions; (B) coplanar structure with two 21-membered-rings and one 18-membered-ring; and (C,D) the 3D structure and simplified 4-connected Wei topology of $\mathbf{1}$.

\subsection{Electrocatalytic Activity}

As mentioned above, a myriad of previous reports have indicate that MOFs always show high catalytic activity in plenty of catalytic processes due to their large surface area, unique porosity, and tailorable functionality. However, MOFs used as OER catalyst are seldom reported. Therefore, to test the catalytic performance of $\mathbf{1}$ for electrochemical oxidation of water to dioxygen, $\mathbf{1}$ was loaded onto a glassy carbon electrode using Nafion as binder to investigate the electrocatalytic activity of $\mathbf{1}$ in alkaline electrolytes.

Figure 2A gives LSV curves of $\mathbf{1}$ in an $\mathrm{O}_{2}$-saturated $0.1,1.0$ and $2 \mathrm{M} \mathrm{KOH}$ solution with a scan rate of $10 \mathrm{mV} \cdot \mathrm{s}^{-1}$. As can be seen, the electrocatalytic OER activity of 1 significantly increases with enhancing the concentration of $\mathrm{KOH}$ solution, indicating that a high concentration of $\mathrm{KOH}$ is beneficial for the improvement of OER performance, which is in good agreement with previous observations in other electrocatalytic systems $[35,43,44]$. As a comparison, $\mathrm{Co}_{3} \mathrm{O}_{4}$, purchased fromAlfa Aesar(China) Chemicals Co., Ltd., Shanghai, China, was loaded onto a glassy carbon electrode to test the electrocatalytic activity in the same conditions. Figure 2B shows the LSV curves of the different catalysts in $1.0 \mathrm{M} \mathrm{KOH}$ solution with a scan rate of $10 \mathrm{mV} \cdot \mathrm{s}^{-1}$. The OER onset potential of 1 is estimated to be about $1.51 \mathrm{~V}$ (vs. RHE), which is earlier than that of the benchmark $\mathrm{Co}_{3} \mathrm{O}_{4}$ counterpart $(1.61 \mathrm{~V}$ vs. RHE). For practical purposes, one is required to apply a high overpotential in order to have significant magnitude of current density. The overpotential required to reach a current density of $10 \mathrm{~mA} \mathrm{~mA} \cdot \mathrm{cm}^{-2}$ $\left(\eta_{10}\right)$ is chosen because it is a metric associated with solar fuel synthesis. As can be seen in Figure 2B, 1 delivers a current density of $10 \mathrm{~mA} \cdot \mathrm{cm}^{-2}$ at an overpotential of $1.59 \mathrm{~V}$, which is observed to be smaller than that of $\mathrm{Co}_{3} \mathrm{O}_{4}(1.70 \mathrm{~V})$. It is worth pointing out that the $\eta_{10}$ value for $\mathbf{1}$ compares recently reported state of the art Co-based and MOF-based OER catalysts (Table 3) [45-56]. Tafel plots was always employed to estimate the electrocatalytic kinetics. As shown in Figure 2C, the Tafel slope of 1 is $89 \mathrm{mV} \cdot \mathrm{dec}^{-1}$ in $1 \mathrm{M} \mathrm{KOH}$, which is bigger than that of $\mathrm{Co}_{3} \mathrm{O}_{4}\left(73 \mathrm{mV} \cdot \mathrm{dec}^{-1}\right)$, and comparable to that of the previously reported highly active OER catalysts (Table 3) [45-56]. Durability is of great importance for the practicability of catalyst electrode. The stability of $\mathbf{1}$ was examined by continuous cyclic voltammetry (CV) scanning between 1.38 and $1.78 \mathrm{~V} \cdot \mathrm{vs}$. RHE in $1 \mathrm{M} \mathrm{KOH}$ solution at a scan rate of $100 \mathrm{mV} \cdot \mathrm{s}^{-1}$. Interestingly, after 100 cycles, no obvious changes in current density is observed 
from LSV curves indicating a long-term stability of $\mathbf{1}$ in OER processes (Figure 2D). Electrochemical impedance spectroscopy (EIS) was performed to further estimate the kinetics of the catalysts at the electrode and electrolyte interface during the OER process. Figure $3 \mathrm{~A}$ describes the obtained Nyquist plots of 1 and $\mathrm{Co}_{3} \mathrm{O}_{4}$, respectively. Both 1 and $\mathrm{Co}_{3} \mathrm{O}_{4}$ were fitted using the same equivalent circuit, which contained three components: charge-transfer resistance (Rct), solution resistance (Rs), and constant-phase resistance (Rcp). The charge transfer resistance (Rct) at the surface of the catalysts can be confirmed by the diameter of a semicircle at high frequencies in the Nyquist plot. Generally, small Rct value means fast OER kinetics [28,57]. Compared with $\mathrm{Co}_{3} \mathrm{O}_{4}$ in $1.0 \mathrm{M} \mathrm{KOH}$, the Rct values of $\mathbf{1}$ keep the smaller Rct value in $1 \mathrm{M} \mathrm{KOH}$. Hence, such a low Rct value of $\mathbf{1}$ indicates its high charge transfer process at the surface of $\mathbf{1}$ (Table 4). The intrinsic activity of catalysts were also further evaluated by the turnover frequency (TOF) from 343 to $393 \mathrm{mV}$. As depicted in Figure 3B, the TOF on 1 is apparently higher than those of benchmark catalyst $\mathrm{Co}_{3} \mathrm{O}_{4}$ demonstrating the better intrinsic OER activity of $\mathbf{1}$.
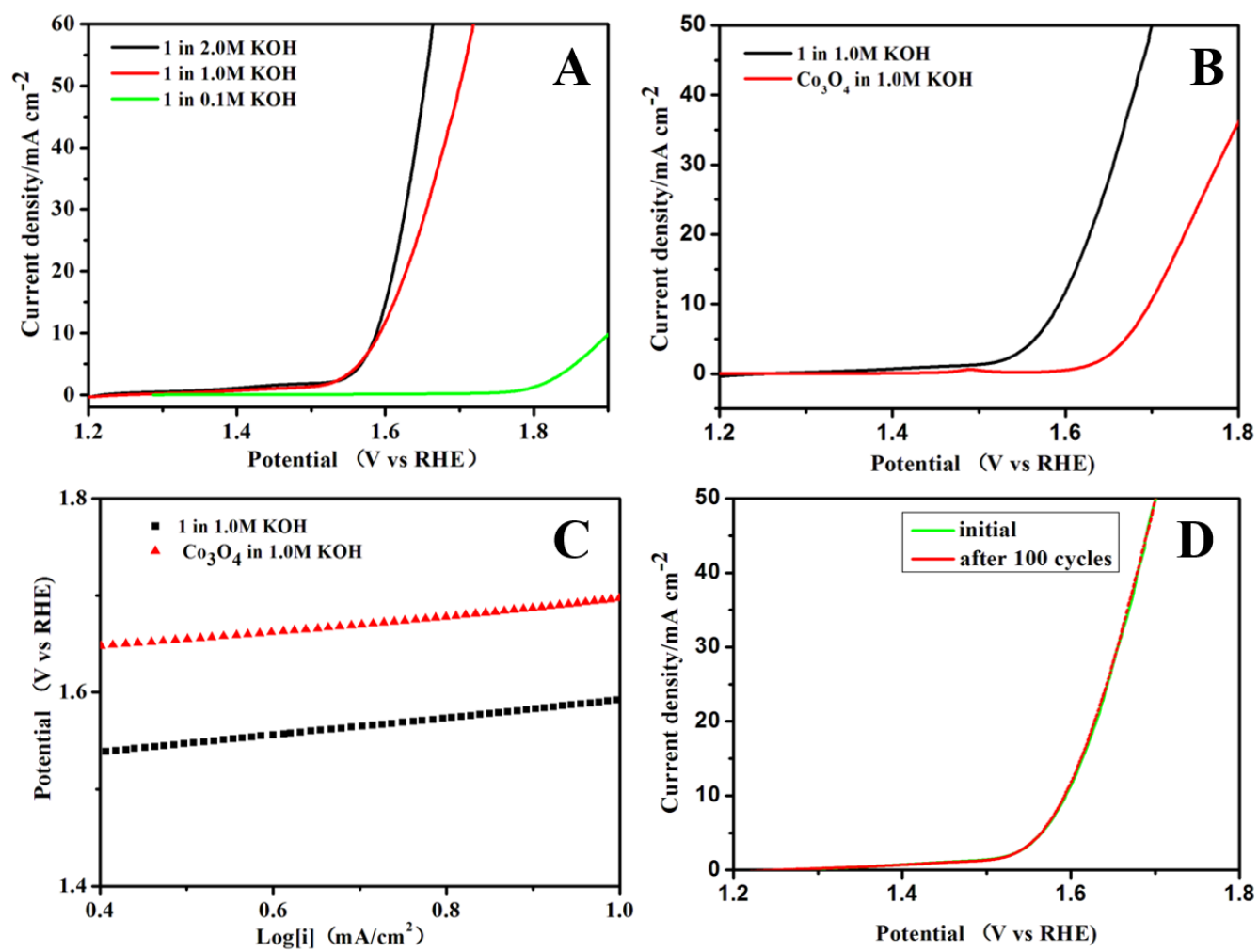

Figure 2. (A) Polarization curves of $\mathbf{1}$ in $0.1 \mathrm{M}, 1 \mathrm{M}$ and $2 \mathrm{M} \mathrm{KOH}$; (B) polarization curve of $\mathbf{1}$ and benchmark $\mathrm{Co}_{3} \mathrm{O}_{4}$ in $1 \mathrm{M} \mathrm{KOH}$; (C) polarization curve derived Tafel plots of 1 and benchmark $\mathrm{Co}_{3} \mathrm{O}_{4}$ in $1 \mathrm{M} \mathrm{KOH}$; and (D) polarization curves for the 1st and 100th potential cycles of 1 in $1 \mathrm{M} \mathrm{KOH}$. 
A

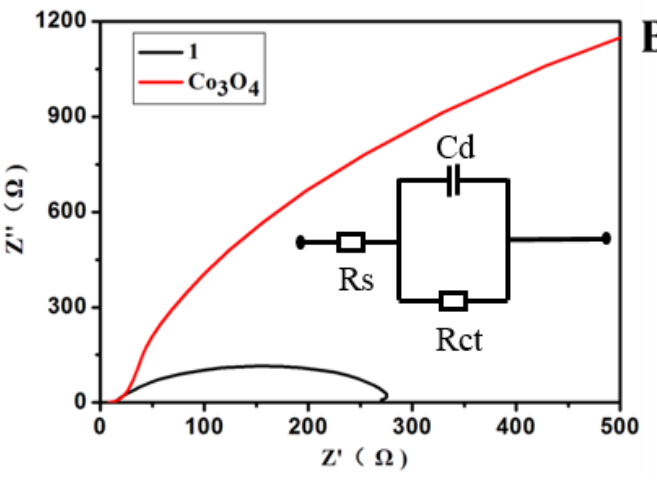

B

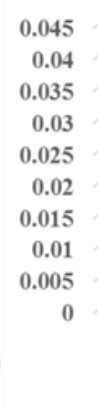

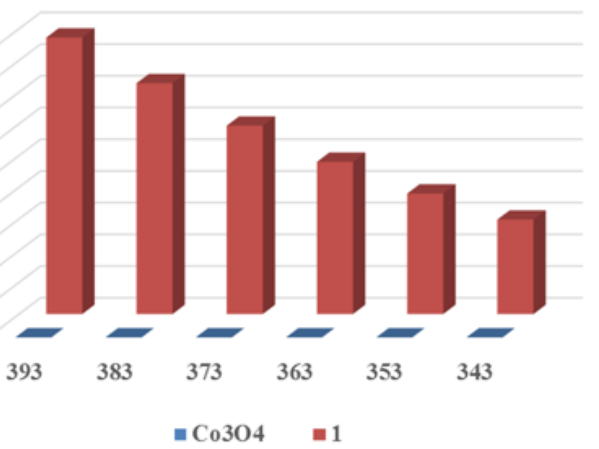

Figure 3. (A) Nyquist plots of $\mathbf{1}$ and benchmark $\mathrm{Co}_{3} \mathrm{O}_{4}$ examined at $0.5 \mathrm{~V}$ (vs. Saturated calomel electrode SCE); and (B) TOFs of $\mathbf{1}$ and benchmark $\mathrm{Co}_{3} \mathrm{O}_{4}$ at different overpotentials from 343 to $393 \mathrm{mV}$.

Table 3. Comparison of OER catalytic performance of recently reported state of the art Co-based and MOF-based OER catalysts.

\begin{tabular}{|c|c|c|c|c|c|}
\hline Catalysts & $\begin{array}{c}\text { Overpotential@10 mA } \\
\mathrm{mA} \cdot \mathrm{cm}^{-2}(\mathrm{mV})\end{array}$ & $\begin{array}{l}\text { Tafel slope } \\
\left(\mathrm{mV} \cdot \mathrm{dec}^{-1}\right)\end{array}$ & Electrolyte & Substrate & References \\
\hline MAFX27-OH & 387 & 60 & $1 \mathrm{M} \mathrm{KOH}$ & Glassy Carbon & [45] \\
\hline UTSA-16 & 410 & 40 & $1 \mathrm{M} \mathrm{KOH}$ & Glassy Carbon & [43] \\
\hline Co-ZIF & $510 @ 1 \mathrm{~mA} \cdot \mathrm{cm}^{-2}$ & 193 & $\mathrm{pH}=13.4$ & FTO & [46] \\
\hline Co-TpBpy & $400 @ 1 \mathrm{~mA} \mathrm{~mA} \cdot \mathrm{cm}^{-2}$ & / & $\mathrm{pH}=7.0$ & Glassy Carbon & [47] \\
\hline CoTPyP & $400 @ 1 \mathrm{~mA} \mathrm{~mA} \cdot \mathrm{cm}^{-2}$ & 1 & $0.1 \mathrm{M} \mathrm{NaOH}$ & FTO & [48] \\
\hline Co-WOC-1 & $390 @ 1 \mathrm{~mA} \mathrm{~mA} \cdot \mathrm{cm}^{-2}$ & 128 & $0.1 \mathrm{M} \mathrm{KOH}$ & $\mathrm{Au}(111)$ single-crystal & [49] \\
\hline $\mathrm{Co}_{3} \mathrm{O}_{4} / \mathrm{NRGO}$ & 420 & 83 & $1 \mathrm{M} \mathrm{KOH}$ & Glassy Carbon & [50] \\
\hline hollow $\mathrm{Co}_{3} \mathrm{O}_{4}$ microtubes & 290 & 84 & $1 \mathrm{M} \mathrm{KOH}$ & Ni foam & [51] \\
\hline $\mathrm{Co}_{3} \mathrm{O}_{4}$ nanosheets & 300 & 68 & $0.1 \mathrm{M} \mathrm{KOH}$ & Ti foil & [52] \\
\hline Co-Bi nanoarray & 411 & 166 & $0.1 \mathrm{M} \mathrm{K}-\mathrm{Bi}$ & Carbon cloth & [53] \\
\hline $\mathrm{Co}_{2} \mathrm{P}$ nanoneedles & 310 & 50 & $1 \mathrm{M} \mathrm{KOH}$ & Glassy Carbon & [54] \\
\hline $\mathrm{NiCo}$ LDH & 367 & 40 & $1 \mathrm{M} \mathrm{KOH}$ & Carbon paper & [55] \\
\hline $\mathrm{CoP}$ & 400 & 57 & $1 \mathrm{M} \mathrm{KOH}$ & Glassy Carbon & [56] \\
\hline $\mathrm{Pb}-\mathrm{TCPP}$ & 470 & 106 & $1 \mathrm{M} \mathrm{KOH}$ & Glassy Carbon & [35] \\
\hline Fe/Ni-BTC@NF & 270 & 47 & $0.1 \mathrm{M} \mathrm{KOH}$ & Nickel foam & [36] \\
\hline Co-MOF & 360 & 89 & $1 \mathrm{M} \mathrm{KOH}$ & Glassy Carbon & Present work \\
\hline
\end{tabular}

Table 4. Summary of fitted EIS data for $\mathbf{1}$ and $\mathrm{Co}_{3} \mathrm{O}_{4}$.

\begin{tabular}{cccc}
\hline Material & $\mathbf{R}_{\mathbf{s}}(\boldsymbol{\Omega})$ & $\mathbf{R}_{\mathrm{ct}}(\boldsymbol{\Omega})$ & $\mathrm{C}_{\mathrm{dl}}(\mathbf{m F})$ \\
\hline $\mathbf{1}$ & 13.4 & 247.0 & 118 \\
$\mathrm{Co}_{3} \mathrm{O}_{4}$ & 14.1 & 408.6 & 0.56 \\
\hline
\end{tabular}

\subsection{X-ray Powder Diffraction Analyses, IR Spectra and Thermal Analyses}

The PXRD pattern was applied to confirm the phase purity of $\mathbf{1}$ (Figure 4A). The simulated XRD pattern for $\mathbf{1}$ was acquired from the crystal data using mercury software. As can be seen, most of the peak positions of simulated are in good agreement with the experimental patterns, indicating the high purity of the samples.

FT-IR spectrum of 1 was also investigated (Figure 4B). As indicated by the IR spectroscopy result of 1 , the sharp bands observed at about 1614 and $1438 \mathrm{~cm}^{-1}$ can be ascribed to symmetric and asymmetric stretching vibrations of carboxylic group, respectively [58,59].

To evaluate the thermal stability and their structural variation with the temperature, TGA of 1 was tested under a $\mathrm{N}_{2}$ atmosphere using polycrystalline samples (Figure $4 \mathrm{C}$ ). Compound $\mathbf{1}$ has three identifiable weight loss steps: The first weight loss before $114^{\circ} \mathrm{C}$ is consistent with the removal of two lattice $\mathrm{H}_{2} \mathrm{O}$ molecules (obsd $4.85 \%$, calcd $4.76 \%$ ). The second one can be ascribe to the removal of four lattice $\mathrm{H}_{2} \mathrm{O}$ molecules (obsd $14.15 \%$, calcd $14.28 \%$ ), which is in the range of $114-348^{\circ} \mathrm{C}$. The third one from 348 to $442{ }^{\circ} \mathrm{C}$ is attributed to the collapse of the framework. 

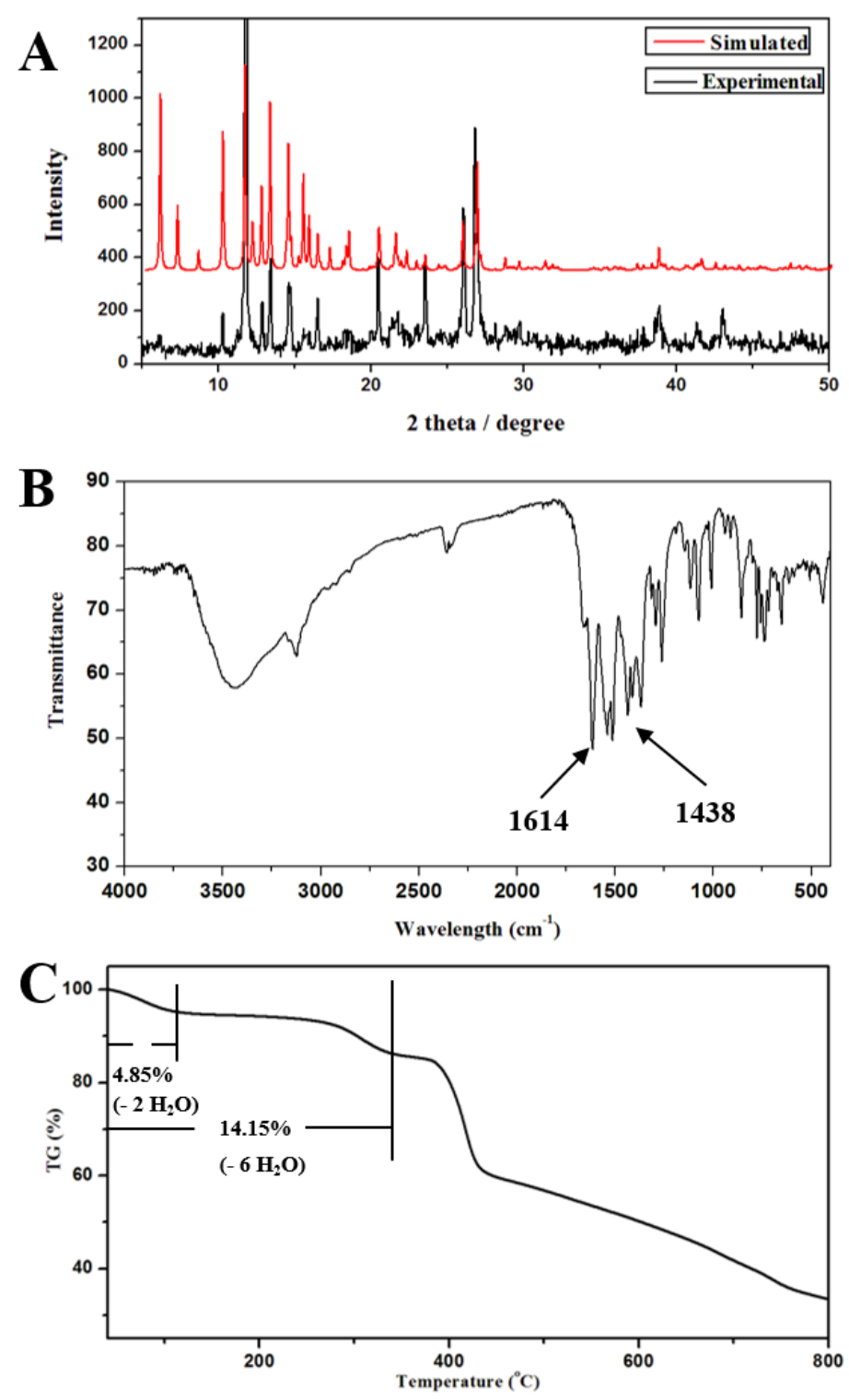

Figure 4. (A) FT-IR spectrum of 1; (B) the powder PXRD pattern and the simulated one from the single-crystal diffraction data of $\mathbf{1}$; and (C) TGA curve of $\mathbf{1}$.

\section{Conclusions}

In summary, a 3D porous framework with a Wei topology has been synthesized by solvothermal reaction of tib, $\mathrm{H}_{3} \mathrm{dcpna}$ and cobalt nitrate. The electrocatalytic activity for water oxidation of $\mathbf{1}$ has been investigated. Compound 1 shows good oxygen evolution reaction (OER) activities in alkaline solution, exhibiting $10 \mathrm{~mA} \cdot \mathrm{cm}^{-2}$ at $\eta=360 \mathrm{mV}$ with a Tafel slope of $89 \mathrm{mV} \cdot \mathrm{dec}^{-1}$, and excellent cycling stability, which is superior to the standard $\mathrm{Co}_{3} \mathrm{O}_{4}$ counterpart. The high OER activity can be ascribed to $1 \mathrm{D}$ open channels along $\mathrm{b}$ axis of $\mathbf{1}$, which expose more activity sites and facilitate the electrolyte penetration.

Acknowledgments: We gratefully thank the financial support of Shandong Provincial Natural Science Foundation (ZR2015BM005), and the Science and Technology Program of Weifang (2017GX014).

Author Contributions: Qingguo Meng and Jitao Lu conceived and designed the experiments; Qingguo Meng and Jianjian Yang performed the experiments; Shixuan Ma and Mujuan Zhai analyzed the data; Jitao Lu wrote the paper.

Conflicts of Interest: The authors declare no conflict of interest. 


\section{References}

1. Li, J.; Zhou, P.; Li, F.; Ren, R.; Liu, Y.; Niu, J.; Ma, J.; Zhang, X.; Tian, M.; Jin, J.; et al. Ni@Pd/PEI-rGO stack structures with controllable Pd shell thickness as advanced electrodes for efficient hydrogen evolution. J. Mater. Chem. A 2015, 3, 11261-11268. [CrossRef]

2. Li, F.; Zhang, L.; Li, J.; Lin, X.; Li, X.; Fang, Y.; Huang, J.; Li, W.; Tian, M.; Jin, J.; et al. Synthesis of Cu-MoS $2 /$ rGO hybrid as non-noble metal electrocatalysts for the hydrogen evolution reaction. J. Power Sources 2015, 292, 15-22. [CrossRef]

3. Suen, N.T.; Hung, S.F.; Quan, Q.; Zhang, N.; Xu, Y.J.; Chen, H.M. Electrocatalysis for the oxygen evolution reaction: Recent development and future perspectives. Chem. Soc. Rev. 2017, 46, 337-365. [CrossRef] [PubMed]

4. Gong, M.; Dai, H. A mini review of NiFe-based materials as highly active oxygen evolution reaction electrocatalysts. Nano Res. 2015, 8, 23-39. [CrossRef]

5. Meng, Y.; Song, W.; Huang, H.; Ren, Z.; Chen, S.; Suib, S. Structure-Property Relationship of Bifunctional $\mathrm{MnO}_{2}$ Nanostructures: Highly Efficient, Ultra-Stable Electrochemical Water Oxidation and Oxygen Reduction Reaction Catalysts Identified in Alkaline Media. J. Am. Chem. Soc. 2014, 136, 11452-11464. [CrossRef] [PubMed]

6. Gong, M.; Zhou, W.; Tsai, M.C.; Zhou, J.; Guan, M.; Lin, M.C.; Zhang, B.; Hu, Y.; Wang, D.Y.; Yang, J.; et al. Nanoscale nickel oxide/nickel heterostructures for active hydrogen evolution electrocatalysis. Nat. Commun. 2014, 5, 4695-4701. [CrossRef] [PubMed]

7. Morales-Guio, C.G.; Stern, L.A.; Hu, X. Nanostructured hydrotreating catalysts for electrochemical hydrogen evolution. Chem. Soc. Rev. 2014, 43, 6555-6569. [CrossRef] [PubMed]

8. Cook, T.R.; Dogutan, D.K.; Reece, S.Y.; Surendranath, Y.; Teets, T.S.; Nocera, D.G. Solar Energy Supply and Storage for the Legacy and Nonlegacy Worlds. Chem. Rev. 2010, 110, 6474-6502. [CrossRef] [PubMed]

9. Suntivich, J.; May, K.J.; Gasteiger, H.A.; Goodenough, J.B.; Shao-Horn, Y. A Perovskite Oxide Optimized for Oxygen Evolution Catalysis from Molecular Orbital Principles. Science 2011, 334, 1383-1385. [CrossRef] [PubMed]

10. Zhao, Y.; Nakamura, R.; Kamiya, K.; Nakanishi, S.; Hashimoto, K. Nitrogen-doped carbon nanomaterials as non-metal electrocatalysts for water oxidation. Nat. Commun. 2013, 4, 2390. [CrossRef] [PubMed]

11. Ma, T.Y.; Dai, S.; Jaroniec, M.; Qiao, S.Z. Graphitic Carbon Nitride Nanosheet-Carbon Nanotube Three-Dimensional Porous Composites as High-Performance Oxygen Evolution Electrocatalysts. Angew. Chem. Int. Ed. 2014, 53, 7281-7285. [CrossRef] [PubMed]

12. Hou, Y.; Wen, Z.; Cui, S.; Ci, S.; Mao, S.; Chen, J. An Advanced Nitrogen-Doped Graphene/Cobalt-Embedded Porous Carbon Polyhedron Hybrid for Efficient Catalysis of Oxygen Reduction and Water Splitting. Adv. Funct. Mater. 2015, 25, 872-882. [CrossRef]

13. Blakemore, J.D.; Crabtree, R.H.; Brudvig, G.W. Molecular Catalysts for Water Oxidation. Chem. Rev. 2015, 115, 12974-13005. [CrossRef] [PubMed]

14. Ma, T.; Dai, S.; Jaroniec, M.; Qiao, S. Metal-Organic Framework Derived Hybrid $\mathrm{Co}_{3} \mathrm{O}_{4}$-Carbon Porous Nanowire Arrays as Reversible Oxygen Evolution Electrodes. J. Am. Chem. Soc. 2014, 136, 13925-13931. [CrossRef] [PubMed]

15. Chen, P.; Xu, K.; Tong, Y.; Li, X.; Tao, S.; Fang, Z.; Chu, W.; Wua, X.; Wu, C. Cobalt nitrides as a class of metallic electrocatalysts for the oxygen evolution reaction. Inorg. Chem. Front. 2016, 3, 236-242. [CrossRef]

16. Frydendal, R.; Paoli, E.A.; Knudsen, B.P.; Wickman, B.; Malacrida, P.; Stephens, I.E.L.; Chorkendorff, I. Benchmarking the Stability of Oxygen Evolution Reaction Catalysts: The Importance of Monitoring Mass Losses. ChemElectroChem 2014, 1, 2075-2081. [CrossRef]

17. Lee, Y.; Suntivich, J.; May, K.J.; Perry, E.E.; Shao-Horn, Y. Synthesis and Activities of Rutile $\mathrm{IrO}_{2}$ and $\mathrm{RuO}_{2}$ Nanoparticles for Oxygen Evolution in Acid and Alkaline Solutions. J. Phys. Chem. Lett. 2012, 3, 399-404. [CrossRef] [PubMed]

18. Reier, T.; Oezaslan, M.; Strasser, P. Electrocatalytic Oxygen Evolution Reaction (OER) on Ru, Ir, and Pt Catalysts: A Comparative Study of Nanoparticles and Bulk Materials. ACS Catal. 2012, 2, 1765-1772. [CrossRef]

19. Vuković, M. Oxygen evolution reaction on thermally treated iridium oxide films. J. Appl. Electrochem. 1987, 17, 737-745. [CrossRef] 
20. Lu, Z.; Wang, H.; Kong, D.; Yan, K.; Hsu, P.C.; Zheng, G.; Yao, H.; Liang, Z.; Sun, X.; Cui, Y. Electrochemical tuning of layered lithium transition metal oxides for improvement of oxygen evolution reaction. Nat. Commun. 2014, 5, 4345. [CrossRef] [PubMed]

21. Sun, Y.; Gao, S.; Lei, F.; Liu, J.; Liang, L.; Xie, Y. Atomically-thin non-layered cobalt oxide porous sheets for highly efficient oxygen-evolving electrocatalysts. Chem. Sci. 2014, 5, 3976-3982. [CrossRef]

22. Gao, M.; Sheng, W.; Zhuang, Z.; Fang, Q.; Gu, S.; Jiang, J.; Yan, Y. Efficient Water Oxidation Using Nanostructured $\alpha$-Nickel-Hydroxide as an Electrocatalyst. J. Am. Chem. Soc. 2014, 136, 7077. [CrossRef] [PubMed]

23. Jung, J.I.; Jeong, H.Y.; Lee, J.S.; Kim, M.G.; Cho, J. A Bifunctional Perovskite Catalyst for Oxygen Reduction and Evolution. Angew. Chem. Int. Ed. 2014, 53, 4582-4586. [CrossRef] [PubMed]

24. Delgado, D.; Minakshi, M.; McGinnity, J.; Kim, D. Co/Mo bimetallic addition to electrolytic manganese dioxide for oxygen generation in acid medium. Sci. Rep. 2015, 5, 15208. [CrossRef] [PubMed]

25. Delgado, D.; Minakshi, M.; Senanayake, G.; Kim, D. Modified electrolytic manganese dioxide (MEMD) for oxygen generation in alkaline medium. J. Solid State Electr. 2015, 19, 1133-1142. [CrossRef]

26. Qu, K.; Zheng, Y.; Dai, S.; Qiao, S. Graphene oxide-polydopamine derived N, S-codoped carbon nanosheets as superior bifunctional electrocatalysts for oxygen reduction and evolution. Nano Energy 2016, 19, 373-381. [CrossRef]

27. Long, X.; Li, J.; Xiao, S.; Yan, K.; Wang, Z.; Chen, H.; Yang, S. A Strongly Coupled Graphene and FeNi Double Hydroxide Hybrid as an Excellent Electrocatalyst for the Oxygen Evolution Reaction. Angew. Chem. Int. Ed. 2014, 53, 7584-7588. [CrossRef] [PubMed]

28. Suntivich, J.; Gasteiger, H.A.; Yabuuchi, N.; Nakanishi, H.; Goodenough, J.B.; Shao-Horn, Y. Design principles for oxygen-reduction activity on perovskite oxide catalysts for fuel cells and metal-air batteries. Nat. Chem. 2011, 3, 546-550. [CrossRef] [PubMed]

29. Deria, P.; Gomez-Gualdróń, D.A.; Hod, I.; Snurr, R.Q.; Hupp, J.T.; Farha, O.K. Framework-Topology-Dependent Catalytic Activity of Zirconium-Based (Porphinato) zinc(II) MOFs. J. Am. Chem. Soc. 2016, 138, 14449-14457. [CrossRef] [PubMed]

30. Wang, K.; Feng, D.; Liu, T.; Su, J.; Yuan, S.; Chen, Y.; Bosch, M.; Zou, X.; Zhou, H. A Series of Highly Stable Mesoporous Metalloporphyrin Fe-MOFs. J. Am. Chem. Soc. 2014, 136, 13983-13986. [CrossRef] [PubMed]

31. Shen, K.; Chen, L.; Long, J.; Zhong, W.; Li, Y. MOFs-Templated Co@Pd Core-Shell NPs Embedded in N-Doped Carbon Matrix with Superior Hydrogenation Activities. ACS Catal. 2015, 5, 5264-5271. [CrossRef]

32. Vilhelmsen, L.B.; Walton, K.S.; Sholl, D.S. Structure and Mobility of Metal Clusters in MOFs: Au, Pd, and AuPd Clusters in MOF-74. J. Am. Chem. Soc. 2012, 134, 12807-12816. [CrossRef] [PubMed]

33. Wang, R.; Wang, Z.; Xu, Y.; Dai, F.; Zhang, L.; Sun, D. Porous Zirconium Metal-Organic Framework Constructed from 2D $\rightarrow 3 \mathrm{D}$ Interpenetration Based on a 3,6-Connected kgd Net. Inorg. Chem. 2014, 53, 7086-7088. [CrossRef] [PubMed]

34. Qin, J.S.; Du, D.Y.; Guan, W.; Bo, X.J.; Li, Y.F.; Guo, L.P.; Su, Z.M.; Wang, Y.Y.; Lan, Y.Q.; Zhou, H.C. Ultrastable Polymolybdate-Based Metal-Organic Frameworks as Highly Active Electrocatalysts for Hydrogen Generation from Water. J. Am. Chem. Soc. 2015, 137, 7169-7177. [CrossRef] [PubMed]

35. Dai, F.; Fan, W.; Bi, J.; Jiang, P.; Liu, D.; Zhang, X.; Lin, H.; Gong, C.; Wang, R.; Zhang, L.; et al. A lead-porphyrin metal-organic framework: Gas adsorption properties and electrocatalytic activity for water oxidation. Dalton Trans. 2016, 45, 61-65. [CrossRef] [PubMed]

36. Wang, L.; Wu, Y.; Cao, R.; Ren, L.; Chen, M.; Feng, X.; Zhou, J.; Wang, B. Fe/Ni Metal-Organic Frameworks and Their Binder-Free Thin Films for Efficient Oxygen Evolution with Low Overpotential. ACS Appl. Mater. Interfaces 2016, 8, 16736-16743. [CrossRef] [PubMed]

37. Bruker. SMART, SAINT and SADABS; Bruker AXS Inc.: Madison, WI, USA, 1998.

38. Sheldrick, G.M. SHELXS-97, Program for X-ray Crystal Structure Determination; University of Gottingen: Gottingen, Germany, 1997.

39. Sheldrick, G.M. SHELXL-97, Program for X-ray Crystal Structure Refinement; University of Gottingen: Gottingen, Germany, 1997.

40. Spek, A.L. PLATON, A Multipurpose Crystallographic Tool; Utrecht University: Utrecht, The Netherlands, 2002.

41. Zhang, L.; Liu, F.; Guo, Y.; Wang, X.; Guo, J.; Wei, Y.; Chen, Z.; Sun, D. Crystal Structure Diversities Based on 4,4'-(2,3,6,7-Tetramethoxyanthracene-9,10-diyl)dibenzoic Acid: From 2D Layer to 3D Net Framework. Cryst. Growth Des. 2012, 12, 6215-6222. [CrossRef] 
42. Zou, K.; Liu, Y.; Jiang, Y.; Yu, C.; Yue, M.; Li, Z. Benzoate Acid-Dependent Lattice Dimension of Co-MOFs and MOF-Derived $\mathrm{CoS}_{2} @ \mathrm{CNT}$ with Tunable Pore Diameters for Supercapacitors. Inorg. Chem. 2017, 56, 6184-6196. [CrossRef] [PubMed]

43. Jiang, J.; Huang, L.; Liu, X.; Ai, L. Bioinspired Cobalt-Citrate Metal-Organic Framework as an Efficient Electrocatalyst for Water Oxidation. ACS Appl. Mater. Interfaces 2017, 9, 7193-7201. [CrossRef] [PubMed]

44. Cheng, N.; Liu, Q.; Asiri, A.M.; Xing, W.; Sun, X. A Fe-doped $\mathrm{Ni}_{3} \mathrm{~S}_{2}$ particle film as a high-efficiency robust oxygen evolution electrode with very high current density. J. Mater. Chem. A 2015, 3, 23207-23212. [CrossRef]

45. Lu, X.F.; Liao, P.Q.; Wang, J.W.; Wu, J.X.; Chen, X.W.; He, C.T.; Zhang, J.P.; Li, G.R.; Chen, X.M. An Alkaline-Stable, Metal Hydroxide Mimicking Metal-Organic Framework for Efficient Electrocatalytic Oxygen Evolution. J. Am. Chem. Soc. 2016, 138, 8336-8339. [CrossRef] [PubMed]

46. Wang, S.; Hou, Y.; Lin, S.; Wang, X. Water Oxidation Electrocatalysis by a Zeolitic Imidazolate Framework. Nanoscale 2014, 6, 9930-9934. [CrossRef] [PubMed]

47. Aiyappa, H.B.; Thote, J.; Shinde, D.B.; Banerjee, R.; Kurungot, S. Cobalt-Modified Covalent Organic Framework as a Robust Water Oxidation Electrocatalyst. Chem. Mater. 2016, 28, 4375-4379. [CrossRef]

48. Wurster, B.; Grumelli, D.; Hotger, D.; Gutzler, R.; Kern, K. Driving the Oxygen Evolution Reaction by Nonlinear Cooperativity in Bimetallic Coordination Catalysts. J. Am. Chem. Soc. 2016, 138, 3623-3626. [CrossRef] [PubMed]

49. Manna, P.; Debgupta, J.; Bose, S.; Das, S.K. A Mononuclear CoII Coordination Complex Locked in a Confined Space and Acting as an Electrochemical Water-Oxidation Catalyst: A “Ship-in-a-Bottle” Approach. Angew. Chem. Int. Ed. 2016, 55, 2425-2430. [CrossRef] [PubMed]

50. Kumar, K.; Canaff, C.; Rousseau, J.; Arrii-Clacens, S.; Napporn, T.W.; Habrioux, A.; Kokoh, K.B. Effect of the Oxide-Carbon Heterointerface on the Activity of $\mathrm{Co}_{3} \mathrm{O}_{4} /$ NRGO Nanocomposites toward ORR and OER. J. Phys. Chem. C 2016, 120, 7949-7958. [CrossRef]

51. Zhu, Y.P.; Ma, T.Y.; Jaroniec, M.; Qiao, S.Z. Self-Templating Synthesis of Hollow $\mathrm{Co}_{3} \mathrm{O}_{4} \mathrm{Microtube}$ Arrays for Highly Efficient Water Electrolysis. Angew. Chem. Int. Ed. 2017, 56, 1324-1328. [CrossRef] [PubMed]

52. Xu, L.; Jiang, Q.; Xiao, Z.; Li, X.; Huo, J.; Wang, S.; Dai, L. Plasma-Engraved $\mathrm{Co}_{3} \mathrm{O}_{4}$ Nanosheets with Oxygen Vacancies and High Surface Area for the Oxygen Evolution Reaction. Angew. Chem. Int. Ed. 2016, 55, 5277-5281. [CrossRef] [PubMed]

53. Ge, R.; Du, H.; Tao, K.; Zhang, Q.; Chen, L. Cobalt-Borate Nanoarray: An Efficient and Durable Electrocatalyst for Water Oxidation under Benign Conditions. ACS Appl. Mater. Interfaces 2017, 9, 15383-15387. [CrossRef] [PubMed]

54. Dutta, A.; Samantara, A.K.; Dutta, S.K.; Jena, B.; Pradhan, N. Surface-Oxidized Dicobalt Phosphide Nanoneedles as a Nonprecious, Durable, and Efficient OER Catalyst. ACS Energy Lett. 2016, 1, 169-174. [CrossRef]

55. Liang, H.; Meng, F.; Cabán-Acevedo, M.; Li, L.; Forticaux, A.; Xiu, L.; Wang, Z.; Jin, S. Hydrothermal Continuous Flow Synthesis and Exfoliation of NiCo Layered Double Hydroxide Nanosheets for Enhanced Oxygen Evolution Catalysis. Nano Lett. 2015, 15, 1421-1427. [CrossRef] [PubMed]

56. Liu, M.; Li, J. Cobalt Phosphide Hollow Polyhedron as Efficient Bifunctional Electrocatalysts for the Evolution Reaction of Hydrogen and Oxygen. ACS Appl. Mater. Interfaces 2016, 8, 2158-2165. [CrossRef] [PubMed]

57. Delgado, D.; Minakshi1, M.; Kim, D. Electrochemical Impedance Spectroscopy Studies on Hydrogen Evolution from Porous Raney Cobalt in Alkaline Solution. Int. J. Electrochem. Sci. 2015, 10, 9379-9394.

58. Wang, H.; Yin, F.; Li, G.; Chen, B.; Wang, Z. Preparation, Characterization and Bifunctional Catalytic Properties of $\mathrm{MOF}(\mathrm{Fe} / \mathrm{Co})$ Catalyst for Oxygen Reduction/Evolution Reactions in Alkaline Electrolyte. Int. J. Hydrogen Energy 2014, 39, 16179-16186. [CrossRef]

59. Ramkumar, R.; Minakshi, M. Fabrication of ultrathin $\mathrm{CoMoO}_{4}$ nanosheets modified with chitosan and their improved performance in energy storage device. Dalton Trans. 2015, 44, 6158-6168. [CrossRef] [PubMed]

(C) 2017 by the authors. Licensee MDPI, Basel, Switzerland. This article is an open access article distributed under the terms and conditions of the Creative Commons Attribution (CC BY) license (http:/ / creativecommons.org/licenses/by/4.0/). 